\title{
MACH KRANK!
}

\section{Enrico Danieli}

Dr. med., Facharzt für Allgemeine Innere Medizin, Mitglied FMH

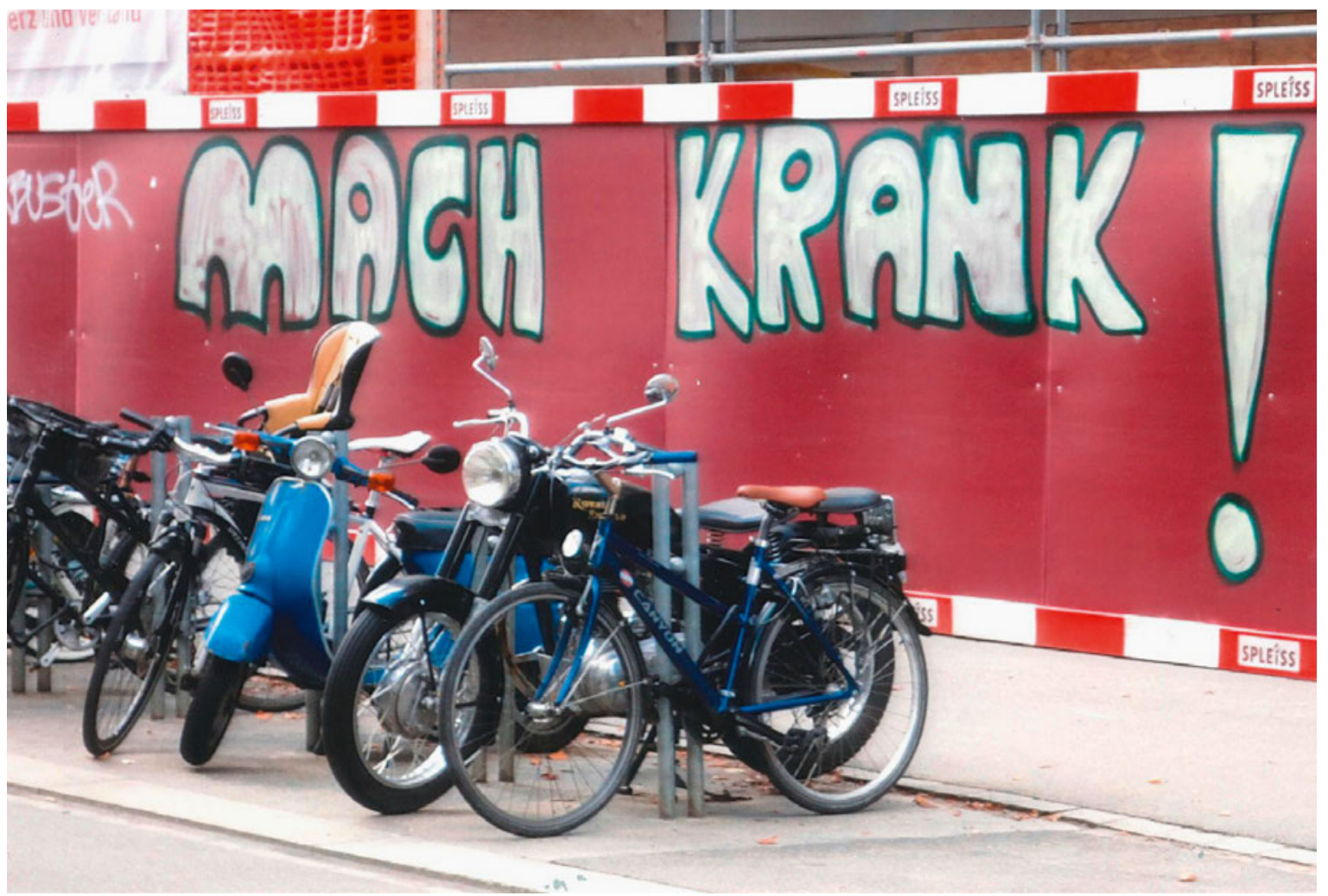

An der roten Bauwand zum Grossprojekt habe ich "es» gefunden. Ja, zugegeben, immer wieder lese ich die Worte, sie entziehen sich meinem Verstand, sind mir fremd. MACH KRANK! Weisse, schwarz umrandete Buchstaben, viel zu langes Ausrufezeichen. Wie soll das gelingen, wenn doch schon die Umkehrung (mach gesund!) unmöglich ist? Sind wir die Ursachen meines Durcheinanders? Machen wir Patienten krank, die nicht krank sind, wenn ich nicht erkenne, dass ein Spiel mit mir gespielt wird, wenn ich Krankhaftes finde, wo nichts ist, nur weil ... So schreiben wir Zeugnisse und sind mehrfach Teil eines Missbrauchs. Lieber wäre mir die Mehrzahl, MACHT KRANK!: hier bestünde die Möglichkeit verschiedener Ursachen: als Form einer Arbeitsverweigerung; oder als Hinweis auf eine schädliche Substanz, in Gebrauch bei den Bauarbeiten. Doch die Einzahl macht mich zum Prellbock: hier der Patient mit seinen beklagten Beschwerden, da die ausnützende, unmenschliche Arbeitssituation. Gleichzeitig verführt der Aufruf zur Lüge. Ist möglicherweise, wer krank ist, unehrlich? Lässt sich besser mit etwas leben als ohne etwas? Ist unsere moralisch reine Vorstellung, dass, wer kommt, übertrieben, gesagt auch krank ist (und dass, aber das ist falsch, wer nicht kommt, immer auch gesund ist)? Aufgrund anarchischer Pinseleien wird unser System aus den Angeln gehoben. Noch suchen wir vergeblich nach dem neuen Standardwerk $(500$ Seiten, 30 farbige Abbildungen, 77 Tabellen) KRANKMACHEN. Bleibt zu hoffen, dass genügend Zeit bleibt für die Gesunden unter den Kranken, nein: für die Kranken unter den Gesunden - oder so ...

Bildnachweis

Enrico Danieli 